\title{
Correction: BRF1 accelerates prostate tumourigenesis and perturbs immune infiltration
}

Carolyn J. Loveridge - Sarah Slater - Kirsteen J. Campbell • Noor A. Nam • John Knight • Imran Ahmad (1) • Ann Hedley - Sergio Lilla $(1)$ - Peter Repiscak - Rachana Patel • Mark Salji - Janis Fleming • Louise Mitchell • Colin Nixon - Douglas Strathdee (D) - Matthew Neilson - Chara Ntala - Sheila Bryson - Sara Zanivan (1) Joanne Edwards $(\mathbb{D}) \cdot$ Craig N. Robson - Carl S. Goodyear $\cdot$ Karen Blyth $(\mathbb{D}) \cdot$ Hing Y. Leung $(\mathbb{D})$

Published online: 19 December 2019

(c) The Author(s) 2020

\section{Correction to: Oncogene}

https://doi.org/10.1038/s41388-019-1106-X

published online 18 November 2019

Following publication of this Article the Authors noted errors in the Supplementary files. A discrepancy occurred in Table S14, as an earlier version of the table was presented instead of the final version. As GeneGo is constantly being updated, the identified pathways for the RNA-seq/Proteomics comparison were slightly different when the analysis was re-run. However, it is important to emphasise that the key top pathways are more or less the same and the complement pathway is still identified as per the original table.

The Supplementary files have been updated online. The scientific conclusions of the paper have not been affected. 